\title{
PARAMETERS AFFECTING THE REDUCTION FACTOR IN PEDESTRIAN LOAD MODEL BASED ON PULSATING STATIONARY FORCE
}

\author{
Dr Ivana Štimac Grandić* \\ University of Rijeka, Faculty of Civil Engineering, Croatia \\ Dr Davor Grandić \\ University of Rijeka, Faculty of Civil Engineering, Croatia \\ Nikola Berić \\ University of Rijeka, Faculty of Civil Engineering, Croatia
}

All dynamic pedestrian load models for serviceability control on pedestrian bridges which can be found in Eurocodes (EC) or guides to EC are based on dynamic load model of single pedestrian. Though the model of moving pulsating force is similar to the real character of pedestrian loading (walking along the bridge) the load model based on stationary pulsating force acting at the most adverse position of the bridge deck may be concurrent in bridge design for the reason of simplicity of acceleration assessment. Pulsating force moving along the bridge span do not produce the same dynamic response as a same pulsating stationary force. Therefore, the amplitude of stationary pulsating force have to be factorised by the reduction factor in a way that both load models (stationary and moving) cause the same maximum structural dynamic response. In this paper the structural parameters (structural system, span length, structural frequency and structural damping) affecting the reduction factor in pedestrian load model based on stationary pulsating force are researched. From conducted analyses it can be concluded changes in structural frequency does not affect the reduction factor, while changes in structural damping, structural system and span length affect the reduction factor, i.e. reduction factor is not a constant value as it is defined in load models proposed in some codes or guides.

Key words: Structures, Reduction factor, Pedestrians, Load modeling, Bridging, Pedestrian Bridge

\section{INTRODUCTION}

According to current European norm EN 1990 [09] a verification of the comfort criteria for serviceability due to pedestrian traffic should be performed if the fundamental frequency of the bridge deck is less than $5 \mathrm{~Hz}$ for vertical vibration and $2,5 \mathrm{~Hz}$ for horizontal lateral and torsional vibrations.

To satisfy the serviceability limit state in relation to vibration due to pedestrians the maximum value of dynamic response of the bridge deck should be smaller than the value of comfort criteria defined through the corresponding value of bridge deck dynamic response.

To conduct the dynamic analysis of the pedestrian bridge due to pedestrian traffic appropriate dynamic models of pedestrian loads and comfort criteria should be defined (EN 1991-2 [10]).

The comfort criteria, in terms of maximum ac- ceptable accelerations of any part of the bridge deck can be found in EN 1990 as recommended maximum values, but also the comfort criteria may be defined in the National Annex of EN 1991-2 or may be defined for individual project. The dynamic models of pedestrian loads, according to EN 1991-2, may be defined in the National Annex or for the individual project. Unfortunately, in EN 1991-2 there are no recommended models and many European countries did not define them in their National Annexes (e.g. Croatia [11], Romania [18], Germany [04] and Austria [17]).

In such case the designer may use the dynamic models of pedestrian loads defined in some other National Annex (e.g. British [16]), or in some guide for design of pedestrian brides according to Eurocode $[15,08,06,07,03]$ to calculate the maximum acceleration of the bridge deck. Also the designer can determine the maximum acceleration of bridge deck composed of simply sup 
ported beams or trusses and 2 or 3 span continuous beams using simple analytical formulae presented in ENV 1995-2 [05], EN 1995-5 [09] or other literature sources $[08,19,02]$.

All dynamic pedestrian load models which can be found in codes of guides $[16,15,08,06,07$, 03, 13,14] are based on dynamic load model of single pedestrian. Single pedestrian load model is defined, in general, in two ways: (1) as a pulsating force moving over the bridge deck with a certain constant speed $[16,15,07,03,05,13,14]$, (2) or as a pulsating stationary force acting at the most adverse position of the bridge deck; time of force acting is identical to time needed to force cross the bridge deck with the certain constant speed $[08,06]$.

The analytical formulae for determination of maximum acceleration of simple structures are based on response of single degree of freedom oscillator due to single pedestrian pulsating stationary force of limited or unlimited duration.

Though the model of moving pulsating force is similar to real character of pedestrian loading (walking along the bridge) the load model based on pulsating stationary force may be concurrent in bridge design for the reason of simplicity of acceleration assessment and lack of easily available software able to conduct dynamic analysis due to moving loads.

Although it is easier to obtain the maximum acceleration due to pulsating stationary force it is necessary to establish a convenient stationary load model (i.e. the stationary load model which produces the same maximum dynamic response of a structure as the moving load model).

The dynamic load model of single pedestrian in vertical direction $F v(t)$ is usually defined as pulsating harmonic force presented in Eq. (1) $[16,15,08,06,05,13]$

$$
F_{v}(t)=G_{1} \cdot \sin \left(2 \cdot \pi \cdot f_{v} \cdot t\right)
$$

where $G_{1}$ is amplitude of the pulsating force and $\mathrm{fv}$ is fundamental bridge frequency in vertical direction and $t$ is the time.

Pulsating force moving along the bridge span with a certain constant speed do not produce the same maximum dynamic response as a same pulsating stationary force acting at the most adverse position of the bridge deck with limited duration, where duration equals the time needed to moving force cross the span. The reason of mentioned difference is the variation of the mode shape amplitude along the walking path in the case of moving force.

Therefore, the amplitude of stationary pulsating force have to be factorised by the reduction factor in a way that both load models (stationary and moving) cause the same maximum structural dynamic response. The reduction factors proposed in load models based on stationary pulsating force in codes or guides $[08,06,05,09,01]$ are introduced as the constant value even though it is known that constant factor could not involve all possible situations produced by different bridge structures.

This paper, for reason of simplicity, deals only with single beam structures though the model of stationary pulsating force can be used for any structural system (such as continuous beams, arches or cable-stayed systems).

In this paper the structural parameters (structural system, span length, structural frequency and structural damping) affecting the reduction factor in pedestrian load model based on stationary pulsating force will be researched. Only the vertical component of the pedestrian load will be in focus in this paper.

\section{CALCULATION OF THE MAXIMUM ACCELERATION}

In this chapter, the calculation of the maximum acceleration will be done for stationary and moving pulsating force defined as in Eq. (1) for following structural parameters:

a) bridge structural system: simple supported beam and fixed beam

b) span length L: $15 \mathrm{~m}$ and $20 \mathrm{~m}$

c) structural natural vertical frequency fv: $1 \mathrm{~Hz}$ to $5 \mathrm{~Hz}$ (in steps of $0.4 \mathrm{~Hz}$ )

d) structural damping $\zeta: 0,5 \%, 1 \%, 1,5 \%, 2 \%$

Structural dynamic analysis of each bridge deck is done using software DARK [20], suitable for static and dynamic analysis of 2D beam structures due to moving or stationary, pulsating or constant force.

The deck structure with the span length $L$ is modeled using $n$ beam finite elements. Each finite element is defined by the following geometrical, material, and cross-sectional properties: element length $\Delta \mathrm{L}=\mathrm{L} / \mathrm{n}$, dynamic modulus of elasticity $\mathrm{Ed}$, moment of inertia I, specific weight $\gamma$, and crosssectional area $A$ of the bridge deck. 
For conduction of dynamic analysis, it is also necessary to specify the structural damping $\zeta$, number of time steps $m$, duration of each time step $\Delta t$, force speed $v$ and amplitude of pulsating force $G_{1}$. The relationship between the number of time steps and the duration of a time step is $\mathrm{m}=\mathrm{T} / \Delta \mathrm{t}$ where the total time $\mathrm{T}$ of the force acting equals the time needed for the pedestrian to cross the span $L(T=L / v)$. All numerical models taken into analyses in this paper consist of $n=50$ beam elements, each length of $\Delta \mathrm{L}=\mathrm{L} / 50$.

The bridge deck structure in all analysed structural variants has the same bridge deck crosssection width $b=4 \mathrm{~m}$, dynamic modulus of elasticity $\mathrm{Ed}=3.36 \times 10^{7} \mathrm{kN} / \mathrm{m}^{4}$ and specific weight $\gamma=25 \mathrm{kN} / \mathrm{m}^{3}$.

The heights $\mathrm{h}$ of the bridge deck cross-section for simple supported (ss) and fixed (fix) bridge decks of $15 \mathrm{~m}$ and $20 \mathrm{~m}$ length, taken into analyses, can be seen in Table 1 in dependence of the first vertical frequency $f_{v^{*}}$. The dynamic analyses are conducted using $m=1000$ time steps, each in duration of $\Delta t=T / 1000$. The force speed is taken as $v=0.9 x f v$ as it is defined in $[9,10,13,17]$ and the amplitude of pulsating force $G_{1}=280 \mathrm{~N}$ [07-13].

Table 1: The heights of the bridge deck for simple supported and fixed bridge decks of $15 \mathrm{~m}$ and $20 \mathrm{~m}$ length in dependence of the first vertical frequency

\begin{tabular}{|c|c|c|c|c|}
\hline$f_{v}[H z]$ & $h_{15}{ }^{\text {ss }}[\mathrm{m}]$ & $h_{20}{ }^{\text {ss }}[\mathrm{m}]$ & $\mathrm{h}_{15}{ }^{\text {fix }}[\mathrm{m}]$ & $\mathrm{h}_{20}{ }^{\text {fix }}[\mathrm{m}]$ \\
\hline 1 & 0.137 & 0.243 & 0.060 & 0.107 \\
\hline 1.4 & 0.191 & 0.340 & 0.084 & 0.150 \\
\hline 1.8 & 0.246 & 0.437 & 0.109 & 0.193 \\
\hline 2.2 & 0.301 & 0.534 & 0.133 & 0.236 \\
\hline 2.6 & 0.355 & 0.632 & 0.157 & 0.279 \\
\hline 3 & 0.410 & 0.729 & 0.181 & 0.322 \\
\hline 3.4 & 0.464 & 0.826 & 0.205 & 0.364 \\
\hline 3.8 & 0.519 & 0.923 & 0.230 & 0.407 \\
\hline 4.2 & 0.574 & 1.020 & 0.253 & 0.450 \\
\hline \hline 4.6 & 0.628 & 1.117 & 0.277 & 0.493 \\
\hline 5 & 0.683 & 1.214 & 0.301 & 0.536 \\
\hline
\end{tabular}

The values of the speed $\mathrm{V}$ of the moving force and total acting time $T$ for bridge decks of $15 \mathrm{~m}$ length $\left(T_{15}\right)$ and bridge decks of $20 \mathrm{~m}$ length $\left(T_{20}\right)$ in dependence of the first vertical frequency fv are presented in Table 2.
Table 2: The speed of the moving force and acting time for bridge decks of $15 \mathrm{~m}$ and $20 \mathrm{~m}$ length in dependence of the first vertical frequency

\begin{tabular}{|c|c|c|c|}
\hline $\mathrm{fv}[\mathrm{Hz}]$ & $\mathrm{v}[\mathrm{m} / \mathrm{s}]$ & $\mathrm{T}_{15}[\mathrm{~s}]$ & $\mathrm{T}_{20}[\mathrm{~s}]$ \\
\hline 1 & 0.90 & 16.667 & 22.222 \\
\hline 1.4 & 1.26 & 11.905 & 15.873 \\
\hline 1.8 & 1.62 & 9.259 & 12.346 \\
\hline 2.2 & 1.98 & 7.576 & 10.101 \\
\hline 2.6 & 2.34 & 6.410 & 8.547 \\
\hline 3 & 2.70 & 5.556 & 7.407 \\
\hline 3.4 & 3.06 & 4.902 & 6.536 \\
\hline 3.8 & 3.42 & 4.386 & 5.848 \\
\hline 4.2 & 3.78 & 3.968 & 5.291 \\
\hline 4.6 & 4.14 & 3.623 & 4.831 \\
\hline 5 & 4.50 & 3.333 & 4.444 \\
\hline
\end{tabular}

The calculated values of maximum bridge deck acceleration due to moving pulsating force and stationary pulsating force for simple supported and fixed decks of span of $L=15 \mathrm{~m}$ and $\mathrm{L}=20 \mathrm{~m}$ in dependence of the first vertical frequency $\mathrm{fv}$ and structural damping $\zeta$ can be seen in Tables 3-6.

\section{CALCULATION OF THE REDUCTION FACTOR}

As it is previously mentioned the reduction factor is, in fact, the ratio between dynamic response of the structure due to pulsating force which moves along the bridge with a certain speed and dynamic response due to the same pulsating force acting at most adverse position of the bridge deck.

In this paper, the reduction factor is determined as the ratio of maximum accelerations due to the same model of moving pulsating force and stationary pulsating force.

The reduction factors for different structural systems and span lengths in dependence with structural damping and structural frequencies are shown in Tables 7-10. 
Table 3: Maximum acceleration [m/ $/ \mathrm{s}^{2}$ ] for simple supported deck of span of $15 \mathrm{~m}$

\begin{tabular}{|c||c|c|c|c||c|c|c|c|}
\hline \multirow{2}{*}{$\mathrm{fv}[\mathrm{Hz}]$} & \multicolumn{4}{|c|}{ Moving pulsating force } & \multicolumn{4}{c|}{ Stationary pulsating force } \\
\cline { 2 - 9 } & \multicolumn{3}{|c|}{$\zeta$} & \multicolumn{3}{c|}{$\zeta$} & \multicolumn{3}{c|}{$\zeta$} \\
\cline { 2 - 9 } & $0.5 \%$ & $1 \%$ & $1.5 \%$ & $2 \%$ & $0.5 \%$ & $1 \%$ & $1.5 \%$ & $2 \%$ \\
\hline 1 & 0.7152 & 0.5875 & 0.4963 & 0.4314 & 1.056 & 0.848 & 0.695 & 0.580 \\
\hline 1.4 & 0.5103 & 0.4193 & 0.3543 & 0.3082 & 0.7537 & 0.7537 & 0.6054 & 0.4959 \\
\hline 1.8 & 0.3954 & 0.3246 & 0.2745 & 0.239 & 0.5859 & 0.471 & 0.386 & 0.322 \\
\hline 2.2 & 0.3246 & 0.2667 & 0.2256 & 0.196 & 0.4795 & 0.385 & 0.3156 & 0.2632 \\
\hline 2.6 & 0.2738 & 0.2248 & 0.19 & 0.1654 & 0.4056 & 0.3257 & 0.2667 & 0.2227 \\
\hline 3 & 0.2381 & 0.1956 & 0.1654 & 0.1434 & 0.3517 & 0.2824 & 0.2315 & 0.193 \\
\hline 3.4 & 0.21 & 0.1726 & 0.1459 & 0.1269 & 0.3102 & 0.2492 & 0.2042 & 0.1705 \\
\hline 3.8 & 0.1878 & 0.1544 & 0.1304 & 0.1136 & 0.2775 & 0.2229 & 0.1823 & 0.1525 \\
\hline 4.2 & 0.1695 & 0.1392 & 0.1176 & 0.1023 & 0.2511 & 0.2017 & 0.1652 & 0.1378 \\
\hline 4.6 & 0.1548 & 0.1271 & 0.1074 & 0.0935 & 0.2293 & 0.1841 & 0.1507 & 0.1259 \\
\hline 5 & 0.1425 & 0.1169 & 0.0987 & 0.0860 & 0.2111 & 0.1694 & 0.1387 & 0.1159 \\
\hline \hline
\end{tabular}

Table 4: Maximum acceleration $\left[\mathrm{m} / \mathrm{s}^{2}\right.$ ] for simple supported deck of span of $20 \mathrm{~m}$

\begin{tabular}{|c||c|c|c|c|c|c|c|c|}
\hline \multirow{2}{*}{ fv [Hz ] } & \multicolumn{3}{|c||}{ Moving pulsating force } & \multicolumn{4}{c|}{ Stationary pulsating force } \\
\cline { 2 - 9 } & \multicolumn{3}{|c|}{$\zeta$} & \multicolumn{3}{|c|}{$\zeta$} & \multicolumn{3}{c|}{$\zeta$} \\
\cline { 2 - 9 } & $0.5 \%$ & $1 \%$ & $1.5 \%$ & $2 \%$ & $0.5 \%$ & $1 \%$ & $1.5 \%$ & $2 \%$ \\
\hline 1 & 0.3723 & 0.2936 & 0.2442 & 0.2065 & 0.5612 & 0.4215 & 0.3282 & 0.2637 \\
\hline 1.4 & 0.266 & 0.2099 & 0.1745 & 0.1475 & 0.4009 & 0.3014 & 0.2346 & 0.1884 \\
\hline 1.8 & 0.2062 & 0.1638 & 0.1359 & 0.115 & 0.3116 & 0.2341 & 0.1824 & 0.1463 \\
\hline 2.2 & 0.1692 & 0.1334 & 0.1109 & 0.0938 & 0.255 & 0.1914 & 0.1491 & 0.1197 \\
\hline 2.6 & 0.1432 & 0.1129 & 0.0938 & 0.0794 & 0.2158 & 0.1621 & 0.1261 & 0.1014 \\
\hline 3 & 0.1241 & 0.0979 & 0.0813 & 0.0688 & 0.187 & 0.1404 & 0.1093 & 0.0879 \\
\hline 3.4 & 0.1092 & 0.0868 & 0.0718 & 0.0610 & 0.1651 & 0.124 & 0.0963 & 0.0776 \\
\hline 3.8 & 0.0977 & 0.0776 & 0.0643 & 0.0545 & 0.1477 & 0.1109 & 0.0863 & 0.0694 \\
\hline 4.2 & 0.0886 & 0.0699 & 0.0582 & 0.0492 & 0.1336 & 0.1004 & 0.0782 & 0.0628 \\
\hline 4.6 & 0.0807 & 0.0641 & 0.0531 & 0.0450 & 0.122 & 0.0916 & 0.0713 & 0.0573 \\
\hline 5 & 0.0745 & 0.0587 & 0.0488 & 0.0413 & 0.1122 & 0.0843 & 0.0656 & 0.0527 \\
\hline \hline
\end{tabular}

Table 5: Maximum acceleration $\left[\mathrm{m} / \mathrm{s}^{2}\right]$ for fixed deck of span of $15 \mathrm{~m}$

\begin{tabular}{|c|c|c|c|c|c|c|c|c||}
\hline \multirow{2}{*}{$\mathrm{fv}[\mathrm{Hz}]$} & \multicolumn{4}{|c|}{ Moving pulsating force } & \multicolumn{5}{c||}{ Stationary pulsating force } \\
\cline { 2 - 10 } & \multicolumn{3}{|c|}{$\zeta$} & \multicolumn{3}{|c|}{$\zeta$} & \multicolumn{3}{c||}{$\zeta$} \\
\cline { 2 - 10 } & $0.5 \%$ & $1 \%$ & $1.5 \%$ & $2 \%$ & $0.5 \%$ & $1 \%$ & $1.5 \%$ & $2 \%$ \\
\hline 1 & 1.696 & 1.441 & 1.249 & 1.099 & 3.024 & 2.428 & 1.988 & 1.66 \\
\hline 1.4 & 1.211 & 1.029 & 0.8916 & 0.7849 & 2.159 & 1.733 & 1.42 & 1.185 \\
\hline 1.8 & 0.9485 & 0.805 & 0.7003 & 0.6134 & 1.679 & 1.348 & 1.104 & 0.9217 \\
\hline 2.2 & 0.771 & 0.6548 & 0.5672 & 0.4995 & 1.374 & 1.103 & 0.9034 & 0.7542 \\
\hline 2.6 & 0.6563 & 0.5568 & 0.4844 & 0.4246 & 1.162 & 0.9328 & 0.7643 & 0.6379 \\
\hline 3 & 0.5655 & 0.4802 & 0.4159 & 0.3663 & 1.008 & 0.8091 & 0.6624 & 0.5531 \\
\hline 3.4 & 0.4987 & 0.4237 & 0.3671 & 0.3232 & 0.889 & 0.7137 & 0.5846 & 0.4879 \\
\hline 3.8 & 0.4463 & 0.3791 & 0.3285 & 0.2892 & 0.7954 & 0.6386 & 0.5232 & 0.4366 \\
\hline 4.2 & 0.4065 & 0.345 & 0.3001 & 0.2629 & 0.7196 & 0.5778 & 0.4733 & 0.395 \\
\hline 4.6 & 0.3712 & 0.315 & 0.274 & 0.24 & 0.657 & 0.5274 & 0.4321 & 0.3606 \\
\hline 5 & 0.3414 & 0.2898 & 0.252 & 0.2208 & 0.6044 & 0.4853 & 0.3974 & 0.3318 \\
\hline
\end{tabular}


Table 6: Maximum acceleration [m/ $/ \mathrm{s}^{2}$ ] for fixed deck of span of $20 \mathrm{~m}$

\begin{tabular}{|c|c|c|c||c|c|c|c|c|}
\hline \multirow{2}{*}{$\mathrm{fv}[\mathrm{Hz}]$} & \multicolumn{3}{|c|}{ Moving pulsating force } & \multicolumn{5}{c|}{ Stationary pulsating force } \\
\cline { 2 - 9 } & \multicolumn{3}{|c|}{$\zeta$} & \multicolumn{4}{c|}{$\zeta$} \\
\cline { 2 - 9 } & $0.5 \%$ & $1 \%$ & $1.5 \%$ & $2 \%$ & $0.5 \%$ & $1 \%$ & $1.5 \%$ & $2 \%$ \\
\hline 1 & 0.8869 & 0.7238 & 0.6092 & 0.5263 & 1.538 & 1.158 & 0.904 & 0.729 \\
\hline 1.4 & 0.6346 & 0.5169 & 0.435 & 0.3759 & 1.108 & 0.8333 & 0.6495 & 0.5225 \\
\hline 1.8 & 0.4926 & 0.3997 & 0.3411 & 0.2946 & 0.8517 & 0.6394 & 0.5004 & 0.4034 \\
\hline 2.2 & 0.403 & 0.3289 & 0.2769 & 0.2391 & 0.6989 & 0.5256 & 0.4106 & 0.3309 \\
\hline 2.6 & 0.341 & 0.2783 & 0.2344 & 0.2024 & 0.591 & 0.4443 & 0.3473 & 0.2799 \\
\hline 3 & 0.2958 & 0.2412 & 0.2031 & 0.1754 & 0.5137 & 0.3869 & 0.3019 & 0.2432 \\
\hline 3.4 & 0.2612 & 0.2121 & 0.1808 & 0.1562 & 0.4522 & 0.3402 & 0.2658 & 0.2142 \\
\hline 3.8 & 0.2338 & 0.1898 & 0.1618 & 0.1398 & 0.4047 & 0.3043 & 0.2377 & 0.1916 \\
\hline 4.2 & 0.2112 & 0.1723 & 0.1451 & 0.1253 & 0.3662 & 0.2756 & 0.2152 & 0.1735 \\
\hline 4.6 & 0.1931 & 0.1568 & 0.1336 & 0.1154 & 0.3343 & 0.2514 & 0.1964 & 0.1583 \\
\hline 5 & 0.1774 & 0.1568 & 0.1218 & 0.1052 & 0.3079 & 0.2317 & 0.1809 & 0.1457 \\
\hline
\end{tabular}

Table 7: Reduction factors for simple supported deck of span of $15 \mathrm{~m}$

\begin{tabular}{|c||c|c|c|c|}
\hline \multirow{2}{*}{$\mathrm{fv}[\mathrm{Hz}]$} & \multicolumn{4}{|c|}{$\zeta$} \\
\cline { 2 - 5 } & $0.5 \%$ & $1 \%$ & $1.5 \%$ & $2 \%$ \\
\hline \hline 1 & 0.68 & 0.69 & 0.71 & 0.74 \\
\hline 1.4 & 0.68 & 0.69 & 0.71 & 0.74 \\
\hline 1.8 & 0.67 & 0.69 & 0.71 & 0.74 \\
\hline 2.2 & 0.68 & 0.69 & 0.71 & 0.74 \\
\hline 2.6 & 0.68 & 0.69 & 0.71 & 0.74 \\
\hline 3 & 0.68 & 0.69 & 0.71 & 0.74 \\
\hline 3.4 & 0.68 & 0.69 & 0.71 & 0.74 \\
\hline 3.8 & 0.68 & 0.69 & 0.71 & 0.74 \\
\hline 4.2 & 0.68 & 0.69 & 0.71 & 0.74 \\
\hline 4.6 & 0.68 & 0.69 & 0.71 & 0.74 \\
\hline 5 & 0.68 & 0.69 & 0.71 & 0.74 \\
\hline \hline
\end{tabular}

Table 9: Reduction factors for fixed deck of span of $15 \mathrm{~m}$

\begin{tabular}{|c||c|c|c|c|}
\hline \multirow{2}{*}{$\mathrm{fv}[\mathrm{Hz}]$} & \multicolumn{4}{|c|}{$\zeta$} \\
\cline { 2 - 5 } & $0.5 \%$ & $1 \%$ & $1.5 \%$ & $2 \%$ \\
\hline 1 & 0.56 & 0.59 & 0.63 & 0.66 \\
\hline 1.4 & 0.56 & 0.59 & 0.63 & 0.66 \\
\hline 1.8 & 0.56 & 0.60 & 0.63 & 0.67 \\
\hline 2.2 & 0.56 & 0.59 & 0.63 & 0.66 \\
\hline 2.6 & 0.56 & 0.60 & 0.63 & 0.67 \\
\hline 3 & 0.56 & 0.59 & 0.63 & 0.66 \\
\hline 3.4 & 0.56 & 0.59 & 0.63 & 0.66 \\
\hline 3.8 & 0.56 & 0.59 & 0.63 & 0.66 \\
\hline 4.2 & 0.56 & 0.60 & 0.63 & 0.67 \\
\hline 4.6 & 0.56 & 0.60 & 0.63 & 0.67 \\
\hline 5 & 0.56 & 0.60 & 0.63 & 0.67 \\
\hline
\end{tabular}

Journal of Applied Engineering Science 13(2015)3, 329
Table 8: Reduction factors for simple supported deck of span of $20 \mathrm{~m}$

\begin{tabular}{|c|c|c|c|c|}
\hline \multirow{2}{*}{$\mathrm{fv}[\mathrm{Hz}]$} & \multicolumn{4}{|c|}{$\zeta$} \\
\cline { 2 - 5 } & $0,5 \%$ & $1 \%$ & $1,5 \%$ & $2 \%$ \\
\hline \hline 1 & 0.66 & 0.70 & 0.74 & 0.78 \\
\hline 1.4 & 0.66 & 0.70 & 0.74 & 0.78 \\
\hline 1.8 & 0.66 & 0.70 & 0.74 & 0.79 \\
\hline 2.2 & 0.66 & 0.70 & 0.74 & 0.78 \\
\hline 2.6 & 0.66 & 0.70 & 0.74 & 0.78 \\
\hline 3 & 0.66 & 0.70 & 0.74 & 0.78 \\
\hline 3.4 & 0.66 & 0.70 & 0.74 & 0.79 \\
\hline 3.8 & 0.66 & 0.70 & 0.74 & 0.79 \\
\hline 4.2 & 0.66 & 0.70 & 0.74 & 0.78 \\
\hline 4.6 & 0.66 & 0.70 & 0.74 & 0.79 \\
\hline 5 & 0.66 & 0.70 & 0.74 & 0.78 \\
\hline
\end{tabular}

Table 10: Reduction factors for fixed deck of span of $20 \mathrm{~m}$

\begin{tabular}{|c|c|c|c|c|}
\hline \multirow{2}{*}{$f v[\mathrm{~Hz}]$} & \multicolumn{4}{|c|}{$\zeta$} \\
\cline { 2 - 5 } & $0.5 \%$ & $1 \%$ & $1.5 \%$ & $2 \%$ \\
\hline 1 & 0.58 & 0.63 & 0.67 & 0.72 \\
\hline 1.4 & 0.57 & 0.62 & 0.67 & 0.72 \\
\hline 1.8 & 0.58 & 0.63 & 0.68 & 0.73 \\
\hline 2.2 & 0.58 & 0.63 & 0.67 & 0.72 \\
\hline 2.6 & 0.58 & 0.63 & 0.67 & 0.72 \\
\hline \hline 3 & 0.58 & 0.62 & 0.67 & 0.72 \\
\hline 3.4 & 0.58 & 0.62 & 0.68 & 0.73 \\
\hline \hline 3.8 & 0.58 & 0.62 & 0.68 & 0.73 \\
\hline 4.2 & 0.58 & 0.63 & 0.67 & 0.72 \\
\hline 4.6 & 0.58 & 0.62 & 0.68 & 0.73 \\
\hline 5 & 0.58 & 0.62 & 0.67 & 0.72 \\
\hline
\end{tabular}




\section{DISCUSSION AND CONCLUSION}

In this paper only a short single span deck structures $(15 \mathrm{~m}$ and $20 \mathrm{~m})$ are taken into consideration with variation in structural system, natural frequency and structural damping.

According to results presented in previous chapter it can be concluded that the reduction factor, $R$, is not a constant value as it is defined in model of dynamic stationary pulsating force in some de- sign code or guide (for example $\mathrm{R}=0,59[08,05]$; $R=0,64$ [06]; $R=0,7$ [01] and $R=0,71$ [09]).

As it can be seen from results shown in Tables 7-10 the reduction factors varies slightly with frequency changes. This variation can be attributed to numerical inaccuracy, thus the reduction factor is not affected by frequency changes. Therefore the mean values of calculated reduction factors in relations with frequency are shown in Figure

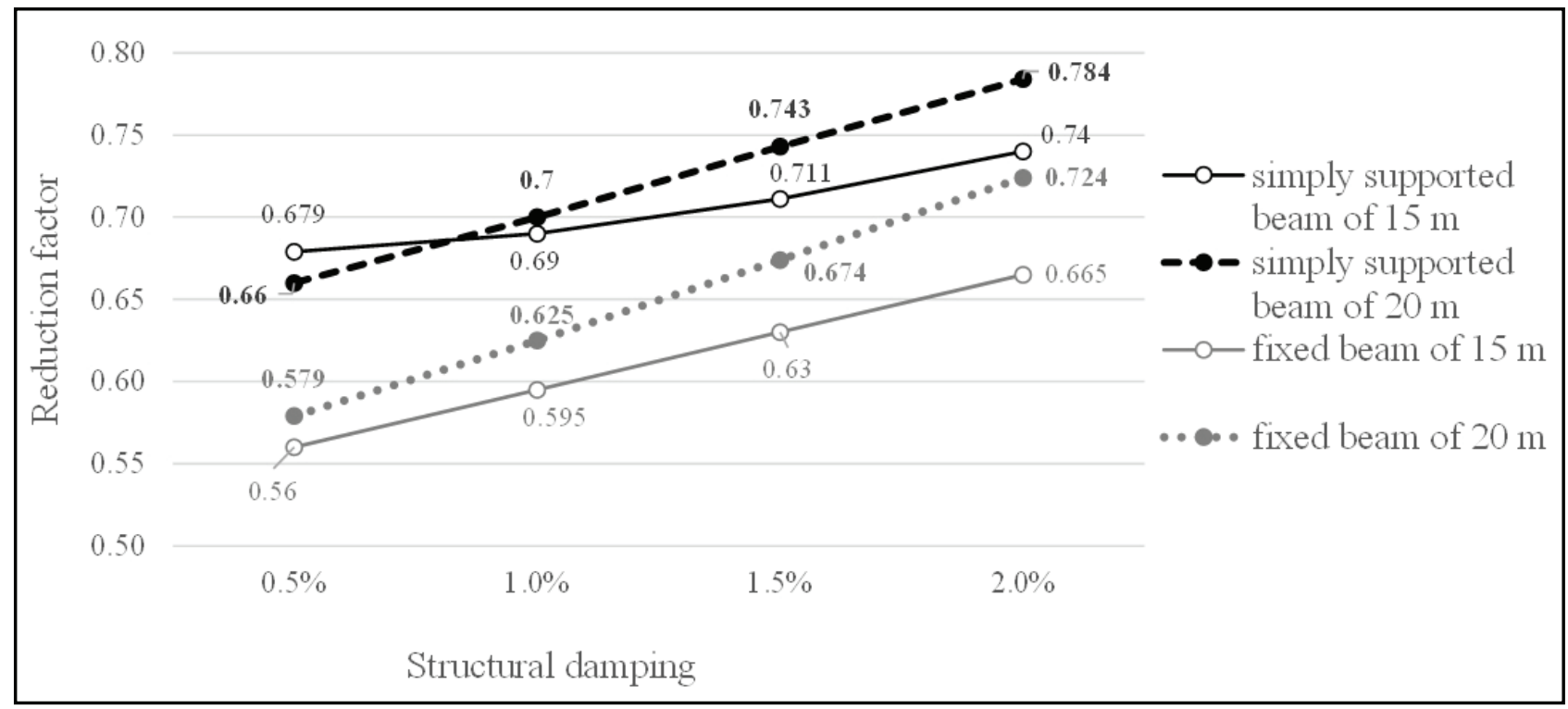

Figure 1: Reduction factor in dependence with structural system, structural damping and span length

In contrary to frequency changes, changes in structural system as well as changes in structural damping and span length result with changes in reduction factor as it can be seen in Figure 1:

a) The reduction factor increase with increasing in structural damping,

b) The reduction factor are greater for longer spans,

c) The reduction factor for fixed beam are smaller than the corresponding values for simply supported beam (for the same span length and structural damping).

Although the paper deals only with short single span bridge deck structures it can be seen that definition of unique value of the reduction factor in model of dynamic stationary pulsating force $[08,06,05,09,01]$ can greatly underestimate (up to $23 \%$ for simply supported deck of 20 m length and $\zeta=2 \%$ if $\mathrm{R}=0,6$ ) or overestimate (up to $25 \%$ for fixed deck of 15 or $20 \mathrm{~m}$ length and $\zeta=0,5 \%$ if $\mathrm{R}=0,7$ ) the maximum deck acceleration due to single pedestrian load model.
As the reduction factor increases with the span length it is expected that the underestimation of maximum acceleration will be even greater for bridge with spans longer than those analysed in this paper. In the future, this research should be expanded to a longer spans, continuous beamlike decks in a way to implement the use of the convenient reduction factor in determination of pedestrian dynamic load model based on stationary pulsating force for beam bridge structures.

\section{ACKNOWLEDGMENT}

This paper is a part of research supported by University of Rijeka through Grant No. 13.05.1.1.01. The authors are grateful for this support.

\section{REFERENCES}

1) Allen, D.E., Murray, T. M. (1993) Design criterion due to walking, Engineering Journal, 30(4), 117-129.

2) Bachnamm, H., et al. (1995) Vibration problems in structures: practical guidelines, Basel: Birkhauser Verlag 
3) Design of footbridges - Human induced Vibration of Steel Structures (HIVOSS), (2008) http://www,stb,rwthaachen, de/projekte/2007/HIVOSS/docs/Footbridge_Background_EN02.pdf , retrieved on October 2nd, 2014.

4) DIN EN 1991-2/NA, Nationaler Anhang - National festgelegte Parameter - Eurocode 1: Einwirkungen auf Tragwerke - Teil 2: Verkhrslasten auf Brucken, (2012) Berlin: Deutches Insitiut fur Normung

5) ENV 1995-2: 1997, Eurocode 5: Design of Timber Structures-Part 2: Bridges, (1997) Brussels: European Committee for Standardization

6) FIB Bulletin 32: Guidelines for the design of footbridges, (2005) Stuttgart: CEB

7) Footbridges: Assessment of vibrational behaviour of footbridges under pedestrian loading, (2006) SETRA, Association Francaise de Dgenie Civil

8) Guide to basis of bridge design related to Eurocodes supplemented by practical design - Handbook 4, (2004) Edited by Luca Sanpaolesi and Pietro Croce, Leonardo da Vinci pilot project, Pisa

9) HRN EN 1990:2011, Eurocode: Basis of structural design (EN 1990:2002+A1:2005+ A1:2005/AC:2010), (2011) Zagreb: Croatian Standard Institute

10) HRN EN 1991-2:2012, Eurocode 1: Actions on structures - Part 2: Traffic loads on bridges (EN 1991-2:2003+AC:2010), (2012) Zagreb: Croatian Standard Institute

11) HRN EN 1991-2:2012/NA, Eurocode 1: Actions on structures - Part 2: Traffic loads on bridges - National Annex, (2012) Zagreb: Croatian Standard Institute

12) HRN EN 1995-2:2013, Eurocode 5: Design of timber structures - Part 2: Bridges (EN
1995-2:2004), (2013) Zagreb: Croatian Standard Institute

13) HRN ENV 1992-2:2004, Eurocode 2 - Design of concrete structures -Part 2: Concrete bridges (ENV 1992-2:1996), (2004) Zagreb: Croatian Standard Institute

14) HRN ISO 10137:2008, Bases for design of structures - Serviceability of buildings and walkways against vibration (ISO 13137:2007), (2008) Zagreb: Croatian Standard Institute

15) Manual for loading and basis of design for road and footbridges (Vejledning til Belastnings- og beregningsgrundlag for vej- og stibroer), (2010) Broer, Vejregel (in Danish)

16) NA to BS EN 1991-2:2003, UK National Annex to Eurocode 1: Actions on structures Part 2: Traffic loads on bridges, (2008) BSI

17) ÖNORM B 1991-2 Eurocode 1: Actions on structures - Part 2: Traffic loads on bridges - National specifications concerning ÖNORM EN 1991-2 and national supplements, (2011) Wien: Austrian Standards plus $\mathrm{GmbH}$ (in German)

18) SR EN 1991-2/NB, Eurocode 1: Actions on structures - Part 2: Traffic loads on bridges - National Annex, (2006) Bucharest: Romanian Standards Association (ASRO

19) Štimac Grandić, I. (2015) Serviceability Verification of Pedestrian Bridges under Pedestrian Loading, Technical Gazette, 22(2), 527537.

20)Štimac, I., Meštrović, D., Kožar, I. (2004) Analiza mostovnih konstrukcija pobuđenih pokretnim opterećenjem, Građevinar, 56(6), 347-353.

Paper sent to revision: 18.02.2015.

Paper ready for publication: 31.08.2015. 